\section{Eisige Therapie}

K ryotherapie scheint bei atopischer Dermatitis wirksam zu sein: In einer Pilotstudie erhielten 18 Patienten mit atopischer Dermatitis nach Absetzen sämtlicher Medikamente über eineinhalb Monate dreimal pro Woche eine Ganzkörperkryotherapie. Dazu begaben sie sich jeweils sehr kurz in drei aufeinander folgende Kammern, in denen eine Lufttemperatur von $-30^{\circ} \mathrm{C},-60^{\circ} \mathrm{C}$ und schließlich $-110{ }^{\circ} \mathrm{C}$ herrschte. 16 Patienten schlossen die Behandlung ab. Der SCORAD-Index ging um etwa 20\% - von 38,7 auf 31,1 - zurück, bei einigen Patienten wurde ein weiterer Abfall in der rund achtwöchigen Follow-up-Phase registriert. Einzige Nebenwirkung waren

\section{Gold im Blut}

D ersonen mit Zahngoldfüllungen haben ein erhöhtes Risiko für Goldkontaktallergien. Bei ihnen ist der Goldgehalt im Blut erhöht und die Konzentration korreliert direkt mit dem Risikoanstieg. Ein ähnliches Ergebnis wurde nun bei Menschen mit Metallkontaktallergie und einem goldbeschichteten Stent gefunden. Auch bei diesen Patienten war der Goldgehalt im Blut erhöht und die Konzentration korrelierte mit der Reaktionsintensität im Goldpatchtest. Bei entsprechenden Patienten mit einem nickelbeschichteten

\section{Exotische Überraschung}

uppen der Seidenraupe (Bombyx mori), frittiert oder gekocht, bereichern den Speiseplan vieler Chinesen. Die Häppchen sind nahrhaft, enthalten aber auch einige Allergene. Anaphylaktische Reaktionen nach Verzehr sind offenbar selten - genaue Zahlen gibt es nicht -, kommen aber vor. Nachdem bereits im Jahr 2003 ein französischer Tourist mit

einer anamnestisch bekannten allergischen Rhinitis nach dem Verkosten einer Seidenraupenpuppe einen schweren Schock erlitten hatte, machten Autoren aus Shenzhen Guangdong, China, im Olympiajahr 2008 die internationale Fachwelt auf diese Gefahr aufmerksam.

$b k$

\section{Ji KM et al. Allergy 2008; 63: 1407-8}

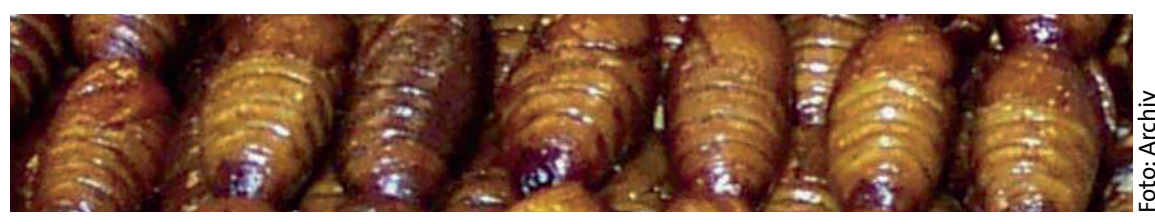

\section{Unterschätzte Viren}

ie banale Erkältung ist vielleicht gar nicht so banal wie oft vermutet. Ein Forscherteam aus dem kanadischen $\mathrm{Cal}-$ gary fand heraus, dass Rhinoviren die Genexpression im befallenen Organismus kräftig aufmischen: 48 Stunden nach Inokulation mit humanen Rhinoviren war in Proben aus der Nasenschleimhaut von Probanden die Aktivität von rund 6.500 Genen verändert. Vor allem Gene, die für die Produktion antiviraler Proteine und proinflammatorischer Zytokine zuständig sind, waren hochaktiv. Das veränderte Expressionsmuster erklärt die üblichen Schnupfensymptome - wie die laufende Nase -, könnte aber auch den Grundstein für ein späteres Asthma legen.

Proud D et al. Am J Respir Crit Care Med 2008; 178: 962-8

\section{Bleibende Erinnerung}

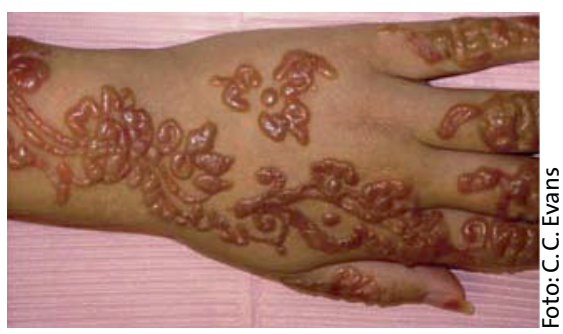

$\mathrm{n}$ Teilen Asiens ist es üblich, dass sich

Hochzeitsgäste temporäre Hennatätowierungen anbringen lassen. Allergische Reaktionen als Folge der Tatoos sind vielfach beschrieben. Sie richten sich meist nicht direkt gegen die Hennainhaltsstoffe, sondern gegen Paraphenylendiamin, das beigemischt wird, um den Farbeffekt zu verstärken. Über einen besonders ausgeprägten Fall berichteten jetzt britische Dermatologen: Bei einer 19-jährigen Frau aus Kuwait stellte sich sechs Tage nach dem Aufbringen Juckreiz im Bereich der Tätowierungen ein. Einen Tag später kam es zur Bläschenbildung. Die Vesikel folgten streng dem floralen Muster des Tätowierung. Eine Behandlung mit topischen Glukortikoiden brachte rasch Erfolg, es blieb aber eine ausgeprägte dauerhafte Hyperpigmentierung zurück. hsf

Evans CC et al. N Engl J Med 2008; 359: 627 